\title{
M00C Construction of General Machinery Equipment Maintenance
}

\author{
Qingcai Liu, Xuechun Wan \\ School of Mechanical and Electrical Engineering, Guangzhou Railway Polytechnic, Guangzhou, China \\ Email: 807431278@qq.com
}

How to cite this paper: Liu, Q. C., \& Wan, X. C. (2021). MOOC Construction of General Machinery Equipment Maintenance. Open Journal of Social Sciences, 9, 147-155. https://doi.org/10.4236/jss.2021.93009

Received: February 7, 2021

Accepted: March 9, 2021

Published: March 12, 2021

Copyright $\odot 2021$ by author(s) and Scientific Research Publishing Inc. This work is licensed under the Creative Commons Attribution International License (CC BY 4.0).

http://creativecommons.org/licenses/by/4.0/

\begin{abstract}
This paper took the MOOC construction of general mechanical equipment maintenance as an example to study its construction. Aspects on course construction foundation, construction objectives, knowledge reconstruction, construction content, implementation effect, existing problems and improvement measures were studied so as to provide reference for the construction of MOOC in higher vocational colleges.
\end{abstract}

\section{Keywords}

MOOC, Equipment Maintenance, Course Construction, Vocational Education

\section{Introduction}

MOOC is also called Massive Open Online Courses (Zhang, 2019). At present, MOOC has rapidly developed into the mainstream form of online open courses. MOOC originated in the United States (Chen, 2018), combining open learning and granulation content. For MOOC, "M" is massive. A traditional course usually has hundreds of students at most, while the number of registered a MOOC can be tens of thousands. The first " $\mathrm{O}$ " is open: Zero foundation, zero cost and easy access, because "MOOC" is open and free for anyone. No matter where a student is, as long as he/she is interested in "MOOC", as long as he/she registers an email with a computer connecting with the internet, he or she can learn the courses across national boundaries (Spector, 2014). The second "O" stands for online. "MOOC" is open 24 hours a day to break constraints of time and space. Students can learn online and interact with each other on the Internet. Anything can be searched or uploaded on the Internet as an information object. " $\mathrm{C}$ " is course, which is a structured set of teaching objectives and objects. These courses aim to train students' expression and thinking ability. Compared with traditional class- 
room teaching and general online courses, MOOC has four prominent features: first, large-scale, no time and space boundary restrictions; second, easy to obtain, low-cost teaching methods; third, targeted, demand-oriented teaching content; fourth, personalized, multi-dimensional teaching guidance. According to investigation, students tend to be attracted by this new type of learning. MOOC takes "learning" as value orientation to impact the traditional teaching mode which focuses on teaching. The core of MOOC is to highlight students' learning and establish the central position of learners.

Since 2013, colleges and universities across China have started construction of MOOC. According to data from Ministry of Education of People's Republic of China, after five years of development, the number of MOOC type courses in China has reached 5000, and the number of college students and social learners selecting MOOC type courses to study has exceeded 70 million (Zhang et al., 2018), and that makes China far ahead of the world in application, production and learning of MOOC. After the Ministry of Education identified 490 national excellent online open courses in 2017, 801 courses were identified as national excellent online open courses in the "Notice of the Ministry of education on announcing the results of the identification of national excellent online open courses in 2018" on January 11, 2019. The construction and application of MOOC have shown explosive growth and achieved a wide range of high-quality resource sharing. MOOC has been recognized by more and more colleges and universities, and China's MOOC construction has entered the forefront of the world. The government will continue to identify thousands of national excellent online open courses, so as to drive more MOOC, promote deep integration of information technology and education/teaching, and make significant progress in improving quality of education and promoting fairness.

Social progress and the development of information technology have put forward new requirements for the course construction of general mechanical equipment maintenance. The rail transit industry in Guangdong Province has developed rapidly in recent years and has a good development prospect in future, which supports long-term and healthy development of economy and social undertakings. The development of rail transit industry needs a large number of high-quality skilled talents. Taking subway as an example, the opening of each new subway line requires construction of more than a dozen stations and at least a vehicle maintenance depot. These stations and vehicle maintenance depot are equipped with a large number of general mechanical equipment, which need to be maintained and managed by special personnel to ensure routine operation of lines and vehicles. These maintenance personnel require a high level of knowledge and skills, continuous learning ability. In order to better cultivate skilled personnel for maintenance of general mechanical equipment, higher vocational colleges need to keep pace with the times and use modern information technology to improve the level of personnel training. MOOC is a typical mode of combining modern information technology with modern teaching, and it has become an effective tool for teaching reform and improving teaching level. 


\section{Foundation of Curriculum Construction}

The construction of MOOC for a curriculum shall have a good foundation and clear orientation in professional curriculum system. Because of reform requirements of higher vocational education to improve quality of personnel training, professional curriculum system often undergoes relatively large adjustments, and that will lead to adjustments in curriculum. Therefore, in order to avoid wasting resources as much as possible, it is not suitable to build MOOC for short time, unclear positioning, temporary and weak foundation courses.

General mechanical equipment maintenance course is the core and characteristic course of mechanical and electrical equipment maintenance and management specialty (Liu \& Wan, 2020). Based on campus platform, the online course was funded and built in 2013, which was open to students from mechanical and electrical majors. 4 years later, the course was identified as top-quality online open course and funded to construct as part of college level quality engineering project. In 2017, the course name was revised to the current "general mechanical equipment maintenance" recommended by the professional steering committee. In 2018, it became a demonstration course of information teaching at college level. In 2018, the course became the core course of national professional teaching resource database of engineering machinery application technology, and relevant construction fund was provided.

In terms of course hardware, the polytechnic invested in construction of general machinery training room and purchased cranes, water pumps, fan and piston type air compressor training equipment, which can meet requirements of practical exercise and online information development of practical training. In particular, the only crane for practical training in China was specially customized, which has greatly facilitated implementation of practical teaching.

In general, the course has clear orientation and distinct characteristics, with excellent soft and hard foundation. Through construction of MOOC, the course can be further improved and be opened to the whole society free of charge, so as to facilitate the elective learning of different majors in the school, and also facilitate learning of students from other schools and enterprises.

\section{Objectives of Curriculum Construction}

The basic purpose of MOOC construction is to build an online open course with complete "learning" and "auxiliary teaching" functions. The course shall make learners as core and have good practicability. In order to adapt to development of information technology and improve training level of general mechanical equipment maintenance talents needed by rail transit industry, based on Intelligent Center of Vocational Education (ICVE) platform, the curriculum content was reconstructed according to requirements of modularization of curriculum structure and granulation of curriculum resources. MOOC shall be able to meet needs of learners, and learners can use MOOC to carry out autonomous learning. 
The ultimate purpose of MOOC construction is application. The fundamental purpose of building MOOC is to serve students and teachers. The application of MOOC includes two aspects, one is students' learning, and the other is teachers' teaching application. The construction of MOOC should take the cultivation of students' professional skills and quality as the main line, make full use of development of mobile information technology, improve information application level of the course, lay foundation for implementation of hybrid teaching of online classroom and actual classroom, change traditional learning method of relying on teachers, classrooms and textbooks, and to a certain extent, change students' mobile device from game machine to learning machine, promoting learners to use MOOC to realize independent personalized learning, development, mutual evaluation and communication, serving students and society. On the other hand, MOOC self-evaluation and statistical functions can be used to assist teachers in teaching evaluation and reduce teaching load. Teachers can analyze characteristics of learners' learning behavior and learning methods according to data automatically recorded by MOOC, so as to realize effective reflection and improvement of curriculum.

By breaking limitation of time and space, MOOC can meet requirements of social learning. With convenience of mobile Internet, the instant accessibility of learning resources can be realized. Through granulation of curriculum resources, it can adapt to the menu type "point" learning mode of continual education for social learners from enterprises. By breaking inter school restrictions, MOOC can provide more autonomous learning resources for students in other schools.

\section{Curriculum Knowledge Reconstruction}

In order to meet requirements of MOOC platform, content of the course must be reconstructed and granulated. There are two reasons for granulation: first, it is convenient for learners to learn; second, based on the principle of knowledge sharing, it is convenient for other teachers to choose and use resources in specified course and organize personalized teaching.

The course content is based on the post demand, focusing on the principle, structure, application and typical fault handling of bridge crane, water pump, centrifugal fan and piston type air compressor equipped in railway and Metro depots and stations. With the idea of simplification, the MOOC divided learning content into four major projects, and the four projects were further divided into 29 tasks, which were then granulated and decomposed into 176 knowledge and skill points. Learners can reduce difficulty of learning by completing relatively simple small knowledge and skill points. Combined with practical training, they can gradually complete learning objectives and master necessary theories and skills. All knowledge and skills points (including practical training skills points) are displayed by video or animation, and learning tasks are completed through the process of autonomous learning, practice and discussion. In the process of 
completing tasks, knowledge is learned, and job skills are gradually mastered, so as to realize "learning while doing". In the process of completing homework, practice, training and maintenance, learners can stop at any time to consult corresponding knowledge and skills points, so as to achieve the goal of "doing while learning".

For social learners, when they need knowledge of a certain content in the process of work, they can log in to MOOC at any time through mobile phones to check the content they need, or they can put forward requirements or discuss the content at any time, and the course team will answer in time. The schematic diagram of curriculum design ideas was shown in Figure 1.

\section{Content of Curriculum Construction}

In order to construct MOOC, after the reconstruction of curriculum content, we should construct curriculum resources. The construction of curriculum resources is the key and difficult point of MOOC development. The construction of curriculum resources directly affects the quality and efficiency of learning. The main work of resource construction is to build learning videos, 3D animation of complex structure, practical operation or training videos, learning text documents corresponding to videos and all kinds of question database.

In the process of resource construction of curriculum knowledge points, each knowledge point corresponds to at least one text document and one learning video made according to the former. For knowledge points with complex structure or strong practicality, it is necessary to make special 3D structure animation

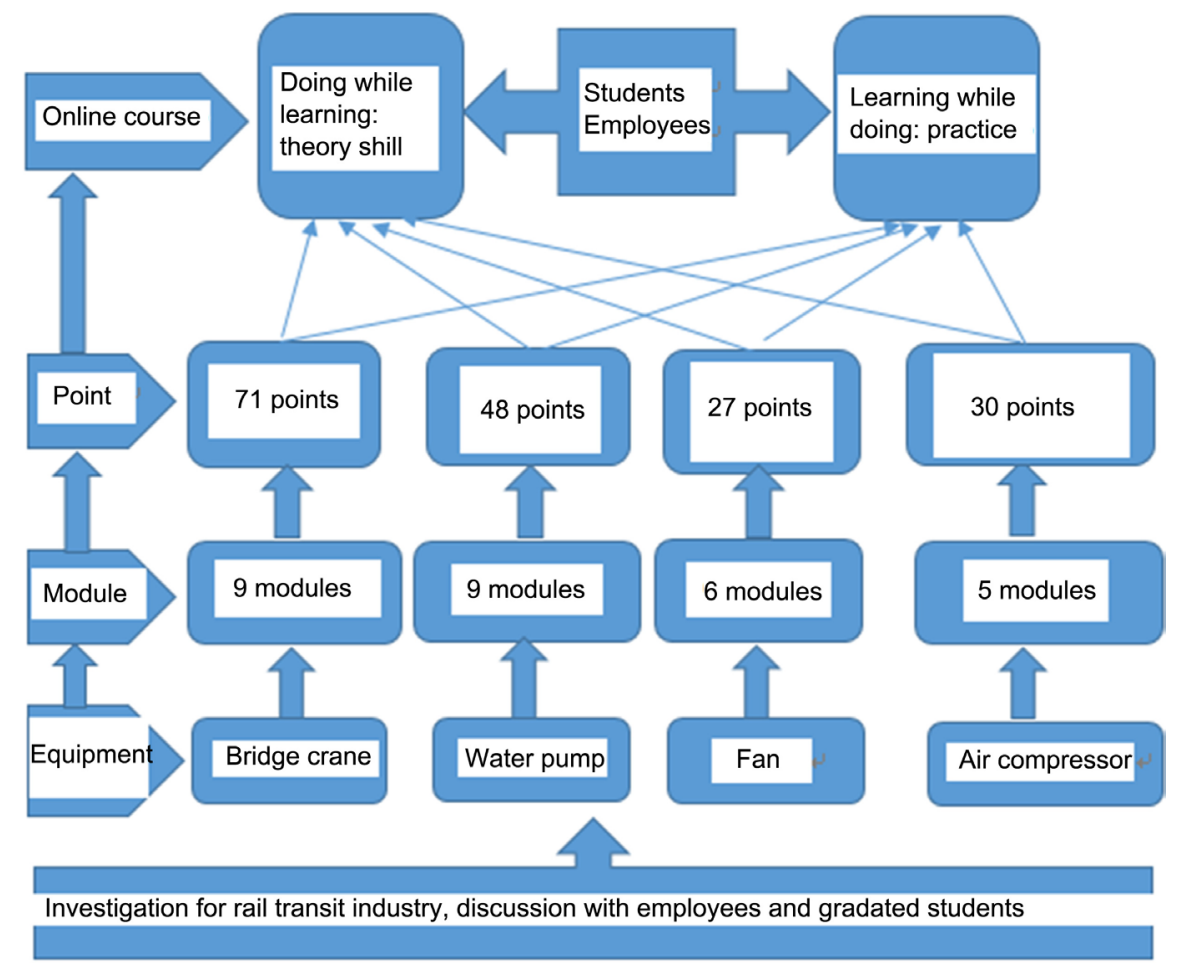

Figure 1. Schematic diagram of curriculum design ideas. 
or shoot practical operation or practice video. Animation or video can be self-made or collected from internet. After learning the knowledge of each module, there are corresponding assignments to be completed, and the assignments correspond to each knowledge point. Each project has set up a test, and after all the projects are completed, there will be a course test.

In order to inspire students' deep thinking, 40 discussion questions were set in the course content for the key links that need to be concerned. After learning the corresponding modules, learners will encounter questions that need to be discussed. Standard answers weren't set up for all discussions and all learners were encouraged to express their opinions freely and share with each other.

The MOOC was offered on the Intelligent Center of Vocational Education platform, with a maximum period of 20 weeks for each phase, which is basically consistent with the term cycle of school. At the beginning of each MOOC phase, all type of homework, test and examination questions can be selected from database to avoid too much repetition.

\section{Curriculum Implementation Effect}

After construction of MOOC, it can be applied. There are two ways of application, one is to set up course for the whole society in MOOC College, and the other is to set up SPOC course for specified school in vocational education cloud, implementing online and offline hybrid teaching. Here, we focused on the first way, offering MOOC for the whole society. At the beginning of each MOOC phase, we need to choose learning content, set homework, tests and examinations, set discussion topics, time span and scoring standards from MOOC resources. During a MOOC phase, it is necessary to issue various course announcements at any time, such as the opening time, learning notes, guidance and so on.

The established MOOC has been open to the whole society for five periods since 2018, mainly used for extracurricular learning, homework, tests and examinations of school students. Figure 2 showed the relevant data at the end of the fifth MOOC phase. According to automatic statistics of Intelligent Center of Vocational Education platform, a total of 18 vocational schools have used the MOOC for teaching.

As can be seen from Figure 2, all kinds of resources are sufficient to meet the learning needs. By the end of the fifth MOOC cycle, the total number of course resources has reached 389, of which 208 are video resources, 176 are PPT type text document resources, and 5 are picture resources. More video resources are convenient for learners to self-study and understand course content. MOOC has 30 sets of homework, 4 sets of tests and 1 set of examination, with a total of 1264 questions. Sufficient homework and tests can effectively improve and deepen learners' mastery of the course.

As shown in Figure 2, the cumulative number of learners in the five MOOCS reached 6756 , and the cumulative number of learners' work units is 279 . The total number of discussions and speeches exceeded 40,000, and the total number of 


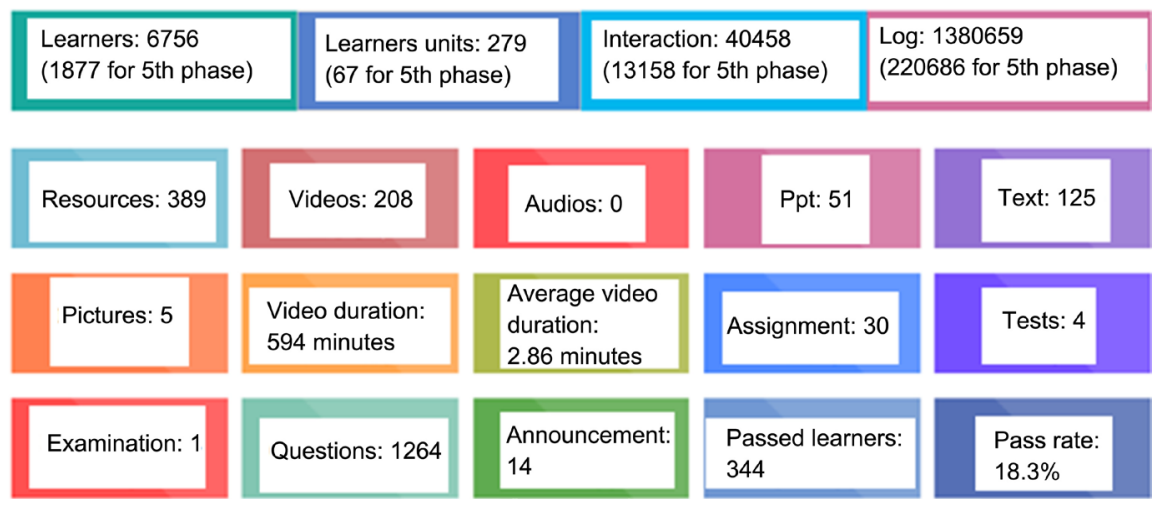

Figure 2. MOOC data.

learning logs exceeded 1.38 million. These data showed that the curriculum which adapted to requirements of learners inside and outside school, was used well and widely, and the curriculum has gotten a certain influence.

For students, after learning each knowledge point, homework practice can effectively consolidate learning effect. The MOOC actually has formed a more vivid textbook, which is convenient for students to use mobile phones or other mobile device to learn anytime and anywhere, without limitation of learning time and space. Compared with traditional teaching, students did more homework, tests and examinations to consolidate and check individual learning effect.

For teachers, MOOC provided a powerful teaching assistant, which can make use of the platform's automatic evaluation, recording and summarizing functions to reduce the burden of teachers' marking homework and increase the number of homework, tests and examinations. Teachers can query students' learning status, study their learning behavior and seek the direction of improvement.

The objective evaluation of students' ordinary performance is not an easy work. From the perspective of learning evaluation ethics, MOOC is also a good yardstick to evaluate the daily learning status of students who choose this course. MOOC can transform the previous qualitative evaluation of ordinary performance into quantitative evaluation. Students' MOOC performance is transparent, and everyone can see progress and performance of other students. This ensures openness, fairness and justice of course performance evaluation. Students can see their own real-time dynamic ranking in the learner group, which also has a certain incentive and promotion effect on their learning motivation.

\section{Problems and Improvements}

There are also some problems in the use of MOOC, among which the most prominent problem is students "course brushing". The so-called "course brushing" means that in order to get credits, students on campus use several mobile phones or computers to play videos at the same time, not for the purpose of learning, just to speed up the speed of playing or browsing course resources.

In order to solve above problem, the background monitoring function was 
added to the course platform. If "course brushing" was found for an account, the account would be temporarily suspended for some time. From perspective of curriculum construction, the course embedded monitoring test questions in each learning video, and questions popped up when the video was played for a certain time, requiring learners to answer before they can continue to play. In addition, the number of subjective questions was increased in the course test database, and the use of subjective questions was increased in homework, test and examination, so as to appropriately increase difficulty of learning. However, if the number of subjective questions is too much, it may exceed the ability of teachers. Therefore, we need a comprehensive balance and corresponding teaching workload management system.

The second problem in the use of MOOC is that mass learners were mainly from school students and teachers, and personnel from enterprises were scattered, which was not as large and concentrated as schools. This reflected the need to increase efforts in spread of course application, invest more resources, and push the MOOC to enterprise employees to learn. It may be a good way to combine the reform of enrollment mode and increase recruitment of enterprise employees, so as to realize the mass use of employees.

\section{Conclusion}

With development of the times and progress of information technology, curriculum construction should keep pace with the times. MOOC is a kind of curriculum model to adapt to development of the times. Through the MOOC construction of general mechanical equipment maintenance course, the goal of course construction was clarified, the course content was reconstructed, and the granulation of course content was realized. The text document, video and animation corresponding to each knowledge point were constructed. In order to consolidate and measure learning effect, a question database with sufficient number of test questions was constructed. From the perspective of application effect, the construction goal has been basically achieved.

The application of MOOC is not perfect. Measures shall be taken to overcome its shortcomings, such as monitoring test questions and increasing subjective test questions. We also need to adjust the management system of teaching workload shall also be adjusted.

\section{Fund}

This article was funded by the 2018 online open courses project of Department of Education of Guangdong (Document No [2018]194 from Guangdong Department of Education) and the 2019 teaching reform project[JY201926] from Guangdong Higher Vocational Machinery Manufacturing Professional Teaching Steering Committee.

\section{Conflicts of Interest}

The authors declare no conflicts of interest regarding the publication of this paper. 


\section{References}

Chen, Z. X. (2018). Research on the Innovation of Teaching Mode of Higher Vocational Education Based on "MOOC". Journal of Chongqing College of Electronic Engineering, 27, 120-124.

Liu, Q. C., \& Wan, X. C. (2020). Study and Practice on Distinctive Characteristics of Mechanical and Electrical Equipment Maintenance and Management Major in Guangzhou Railway Polytechnic. Creative Education, 11, 513-523. https://doi.org/10.4236/ce.2020.114038

Spector, J. M. (2014). Remarks on MOOCS and Mini-MOOCS. Educational Technology Research and Development, 62, 385-392. https://doi.org/10.1007/s11423-014-9339-4

Zhang, F., Yang, Q. X., \& Song, B. Y. (2018). Construction of MOOC of Mechanical Foundation Courses. Journal of Machine Design, 35, 23-25.

Zhang, S. J. (2019). Teaching Practice Research on Information Literacy Education Based on MOOC. Journal of Service Science and Management, 12, 126-131.

https://doi.org/10.4236/jssm.2019.122008 